\title{
Catabolism of Nitrogenous Compounds by Pseudomonas
}

\author{
BY W. L. GABY, C. LOGAN AND S. WHITAKER \\ Department of Microbiology, Hahnemann Medical College, Philadelphia, \\ Pennsylvania, U.S.A.
}

\section{SUMMARY}

The rate of $\mathrm{O}_{2}$ utilization by both pigmented and non-pigmented strains of Pseudomonas aeruginosa was greater with $2 \%(\mathrm{w} / \mathrm{v})$ Casitone as substrate than with $0 \cdot 1 \mathrm{~m}$-glucose as substrate. $P$. aeruginosa readily catabolized Casitone, amino acids and other nitrogenous compounds with the production of an alkaline reaction even in the presence of $0.5 \%(\mathrm{w} / \mathrm{v})$ glucose. Other species of Pseudomonas studied varied in their utilization of these compounds, suggesting a different and possibly satisfactory approach to the identification and classification of species within the genus Pseudomonas.

\section{INTRODUCTION}

The ability of Pseudomonas aeruginosa to produce acid from carbohydrates, in particular from glucose, in amounts sufficient to lower the $\mathrm{pH}$ value of the commonly used carbohydrate media is generally variable and to a large extent depends upon the nitrogenous compounds present in the medium. Simon (1956) stated that the production of blue-green pigment and failure to ferment any of the usual coliform test sugars, except occasionally glucose, are generally regarded as characteristic of ' $P$. pyocyanea'. She found that the fermentation of sugars by Pseudomonas cultures was masked in the peptone medium by the production of free ammonium and a consequently high $\mathrm{pH}$ value. The recent studies of Warren, Ells \& Campbell (1960) indicated that $P$. aeruginosa grown in a glucose ammonium phosphate medium accumulated nitrogenous materials which were oxidized during endogenous respiration. Rhodes (1959) found that after incubation for 7 days in peptone water the $\mathrm{pH}$ values of the media of all Pseudomonas strains studied were between pH 8.3 and pH 8.7. Sherris, Shoesmith, Parker \& Breckon (1959) showed that nearly all of the Pseudomonas strains they tested were able to break down arginine more rapidly than could most other Gram-negative bacilli and suggested that this characteristic might prove to be a useful diagnostic feature. It is evident, therefore, that many of the Pseudomonas species produce an alkaline reaction when grown in the presence of peptides or amino acids. The present study was undertaken to determine the utilization of nitrogenous compounds by several species of Pseudomonas and in particular $P$. aeruginosa.

\section{METHODS}

The strains of Pseudomonas aeruginosa studied were obtained from our stock culture collection and from the diagnostic laboratory. All cultures were identified by the methods described by Gaby \& Free $(1953,1958)$ and included pigmented and non-pigmented varieties. The strains, selected at random, were grown on nutrient agar or in nutrient broth at $37^{\circ}$. Species other than $\boldsymbol{P}$. aeruginosa obtained 
from the American Type Culture Collection were $P$. saccharophilia no. 9114, $\boldsymbol{P}$. oleovorans no. 8062, $\boldsymbol{P}$. ovalis no. 950 (grown at $25^{\circ}$ and $37^{\circ}$ ), $\boldsymbol{P}$. fragi no. 4973, $P$. fluorescens no. 11251, and $P$. mucidolens no. 4685 (grown at $25^{\circ}$ ).

Suspensions of organisms for manometric studies were obtained by growing the bacilli on agar slopes or in shaken flask broth cultures for $18 \mathrm{hr}$. at $25^{\circ}$ or $37^{\circ}$. The organisms were washed thoroughly with saline or phosphate buffer, resuspended in 0.1 M-phosphate buffer, and diluted to give an optical density of 1.35 at $515 \mathrm{~m} \mu$ on a Colman Junior Spectrophotometer Model $6 \mathrm{~A}$. This dilution is equivalent to $6.87 \times 10^{9}$ viable organisms, $12.5 \mathrm{rng}$. wet weight or $2 \cdot 2 \mathrm{mg}$. dry weight of organisms per ml. Oxygen consumption was measured by conventional Warburg techniques.

To determine alkalinity produced by the Pseudomonas species from peptides and amino acids, the various strains were inoculated into a liquid medium containing $(\%, w / v)$ Casitone (Difco) $1 \cdot 0$, glucose $0 \cdot 5$, amino acid $0 \cdot 5$, adjusted to $\mathrm{pH} 7 \cdot 2$ and containing $0.02 \%$ phenol red indicator. The amino acids studied were DL-alanine, DL-serine, and DL-methionine (see Table 1). Asparagine, arginine, leucinamide and glycinamide were also included because of their different amino groupings. The cultures were incubated at either $25^{\circ}$ or $37^{\circ}$, depending upon their optimum temperature requirement, and colour changes of the $\mathrm{pH}$ indicator were noted for periods up to $72 \mathrm{hr}$.

\section{RESULTS}

The results shown in Fig. 1 illustrate the stimulation in the rate of $\mathrm{O}_{2}$ consumption of a representative pigmented strain of Pseudomonas aeruginosa by increasing concentrations of Casitone from $0 \cdot 1$ to $2 \cdot 0 \%(\mathrm{w} / \mathrm{v})$. Three pigmented and three non-pigmented strains tested under these conditions gave essentially the same results. On the other hand, the rate of $\mathrm{O}_{2}$ utilization of four brown (brownishpurple) pigmented strains was only one-half to three-quarters of that shown in Fig. 1. The results in Fig. 2 show that with both pigmented and non-pigmented strains the rate of $\mathrm{O}_{2}$ utilization was greater with $2 \%(\mathrm{w} / \mathrm{v})$ Casitone as substrate than with $0.1 \mathrm{~m}$ glucose. All the strains produced a slight amount of acid in a glucose + peptone basal medium on primary isolation. It is evident from these results that the six $\boldsymbol{P}$. aeruginosa strains tested not only oxidized Casitone at a faster but also more uniform rate than glucose. The results at least partially explain the frequently reported observations that $\boldsymbol{P}$. aeruginosa strains may or may not produce acid in a glucose medium, particularly when the medium contains peptone.

Since Casitone contains amino acids and peptides, experiments were carried out to determine the rate of $\mathrm{O}_{2}$ utilization of Pseudomonas aeruginosa with various single amino acids as substrate. The results in Table 1 show that the rate of $\mathrm{O}_{2}$ utilization by $P$. aeruginosa varied considerably among the 18 different amino acids tested, ranging from $18.5 \mu \mathrm{l} . \mathrm{O}_{2}$ uptake/90 min./mg./dry wt. bacteria with DL-methionine to $74: 1 \mu \mathrm{l} . \mathrm{O}_{2}$ uptake with DL-serine. These results are in agreement with those of Silberman \& Gaby (1961) which showed a correlation between the rate of $\mathrm{O}_{2}$ consumption by $\boldsymbol{P}$. aeruginosa of various amino acids as substrates and the uptake of the corresponding ${ }^{14} \mathrm{C}$ labelled amino acid by the lipid complex of $\boldsymbol{P}$. aeruginosa.

The results in Table 2 list the reactions of the cultures in the media containing the various nitrogenous compounds. All strains of Pseudomonas aeruginosa gave an alkaline reaction within $\mathbf{2 4} \mathrm{hr}$. in the media containing asparagine, arginine, leucinamide and glycinamide with the exception of four strains which required 
$48 \mathrm{hr}$. to produce an alkaline reaction in the media containing glycinamide and leucinamide. Four of the $\boldsymbol{P}$. aeruginosa strains produced either an acid reaction or no indicator colour change in the media containing the four amino acids. The reactions of the other Pseudomonas species in the media differed considerably, not only from $P$. aeruginosa, but also indicated distinct differences between individual species. When peptone was substituted for Casitone in the test medium the results were similar with the exception that alkaline production was less rapid. The other Gram-negative bacilli which normally ferment glucose with the production of much stronger acids continued to do so in the presence of the nitrogenous compounds tested.

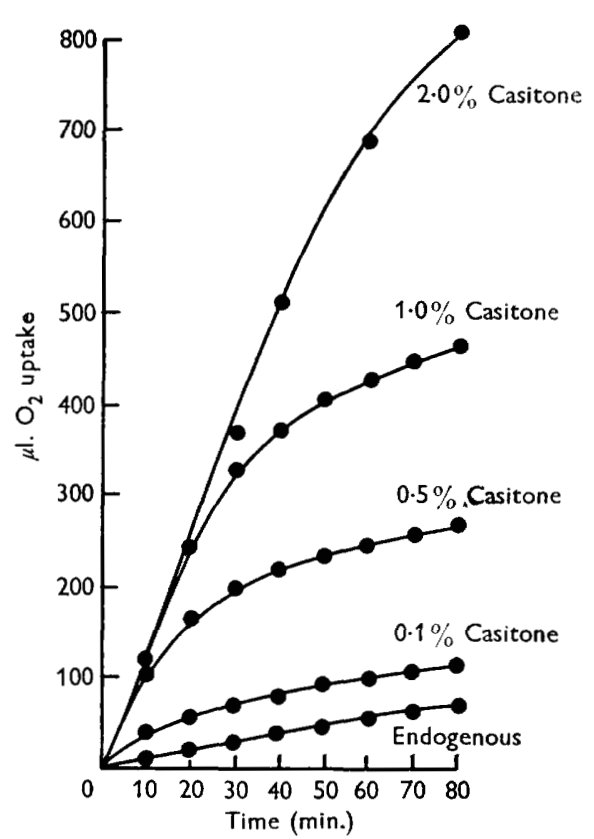

Fig. 1

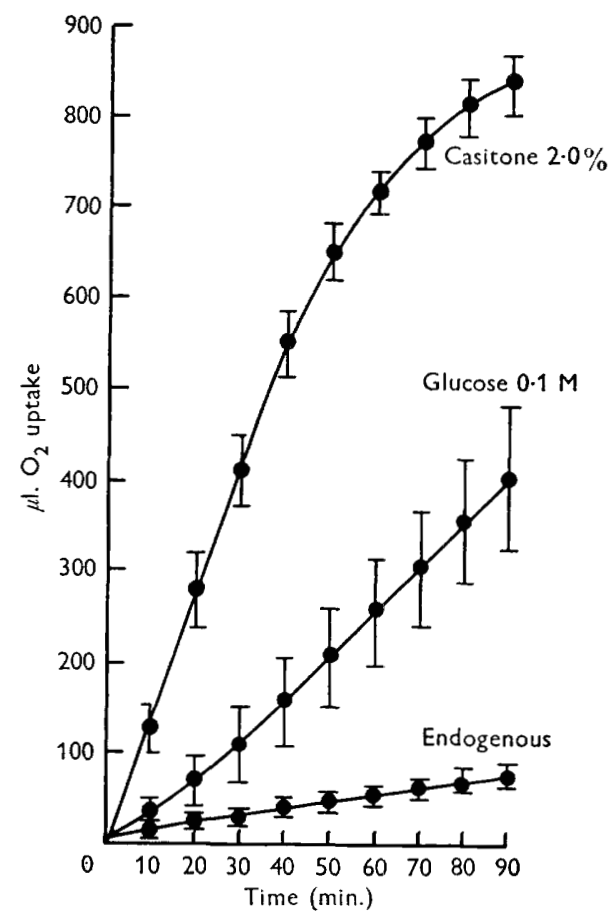

Fig. 2

Fig. 1. The effect of increasing concentrations of Casitone on rate of $\mathrm{O}_{2}$ utilization by $P$. aeruginosa. See legend Table 1, p. 382 for conditions.

Fig. 2. Comparison of the rate of $\mathrm{O}_{2}$ utilization by 6 strains of $P$. aeruginosa with $2 \%$ Casitone and $0 \cdot 1 \mathrm{~m}$ glucose as substrates. Vertical lines represent the extent of individual strain variation. See legend Table 1, p. 382 for conditions.

\section{DISCUSSION}

The results emphasize the ability of Pseudomonas aeruginosa to catabolize nitrogenous compounds. It is of interest to note that there was an excellent correlation found between pigmentation, ability of these strains to utilize nitrogenous compounds, and mouse pathogenicity. The green pigmented and non-pigmented strains of $\boldsymbol{P}$. aeruginosa were found to be weakly pathogenic for mice, whereas $0.5 \mathrm{ml}$. of an 18-24 hr. undiluted broth culture of the brown pigmented strains failed to kill when injected intraperitoneally into mice (Gaby \& Logan, 1961). 
Table 1. Effect of amino acids on $\mathrm{O}_{2}$ uptake by washed suspension of Pseudomonas aeruginosa

The Warburg vessels contained, 2.0 ml. suspension in phosphate buffer $(\mathrm{pH} 7 \cdot 0)$; $1.15 \mathrm{mg}$. amino acid in $0.3 \mathrm{ml}$. phosphate buffer in the side arm; $0.2 \mathrm{ml} .20 \% \mathrm{KOH}$ in the centre well; atmosphere, air; bath temperature $37^{\circ}$.

\begin{tabular}{|c|c|c|c|}
\hline \multirow[b]{2}{*}{ DL-Amino acid substrate } & \multicolumn{2}{|c|}{$\begin{array}{c}\mathrm{O}_{2} \text { uptake }(\mu \mathrm{l} . / 90 \mathrm{~min} . / \mathrm{mg} . \\
\text { bacterial dry wt.) }\end{array}$} & \multirow{2}{*}{$\begin{array}{c}\text { Ratio: } \\
\text { substrate/ } \\
\text { endogenous }\end{array}$} \\
\hline & Endogenous & Substrate & \\
\hline Methionine & $15 \cdot 7$ & $18 \cdot 5$ & $1 \cdot 18$ \\
\hline Hydroxyproline & $20 \cdot 0$ & $24 \cdot 2$ & $1 \cdot 21$ \\
\hline Histidine & $20 \cdot 0$ & $27 \cdot 4$ & $1 \cdot 37$ \\
\hline Cystine* & $20 \cdot 8$ & $28 \cdot 9$ & $1 \cdot 39$ \\
\hline Tyrosine & $15 \cdot 7$ & $22 \cdot 6$ & $1 \cdot 44$ \\
\hline Leucine & $21 \cdot 8$ & $\mathbf{3 2} \cdot \mathbf{5}$ & $1 \cdot 49$ \\
\hline Tryptophane & $18 \cdot 3$ & $29 \cdot 3$ & $1 \cdot 60$ \\
\hline Lysine & $21 \cdot 0$ & $37 \cdot 6$ & 1.79 \\
\hline Glycine & $16 \cdot 4$ & $30 \cdot 8$ & $1 \cdot 84$ \\
\hline Isoleucine & $20 \cdot 8$ & $40 \cdot 5$ & $1 \cdot 94$ \\
\hline Phenylalanine & $21 \cdot 2$ & $45 \cdot 0$ & $2 \cdot 03$ \\
\hline Valine & $17 \cdot 8$ & $36 \cdot 5$ & $2 \cdot 05$ \\
\hline Glutamic acid & $19 \cdot 1$ & $39 \cdot 8$ & $2 \cdot 08$ \\
\hline Cysteine & $18 \cdot 3$ & $37 \cdot 6$ & $2 \cdot 11$ \\
\hline Threonine & $15 \cdot 7$ & $33 \cdot 5$ & $2 \cdot 13$ \\
\hline Asparagine & $21 \cdot 2$ & $45 \cdot 6$ & $2 \cdot 15$ \\
\hline Alanine & $21 \cdot 2$ & $70 \cdot 3$ & $3 \cdot 31$ \\
\hline Serine & $26 \cdot 4$ & $74 \cdot 1$ & $3 \cdot 63$ \\
\hline
\end{tabular}

The limited number of Pseudomonas species studied, other than Pseudomonas aeruginosa, indicated differences in their ability to catabolize nitrogenous compounds. These reactions were consistent on repeated testing and indicate the possibility of using this type of procedure as an aid in differentiating the numerous species with the Pseudomonas genus. There is general agreement among those working in this field that the species comprising the genus are ill-defined, due in part to the emphasis which has been placed on the ability of these bacilli to attack glucose and other sugars either oxidatively or fermentatively. The inadequacy of these commonly used procedures emphasizes the obvious need for the development of new techniques and methods.

Recent publications by Colwell \& Liston (1961) and Rhodes (1961) using the electron computer technique to study the taxonomic relationship among the Pseudomonas, stress the difficulty of species identification within the genus. Most of the cultures examined by Colwell \& Liston (1961) fell into four groups. They were unable, however, to identify rnost of their freshly isolated strains with named strains listed in Bergey's Manual (Breed, Murray \& Smith, 1957). Rhodes (1961) also found that the strains which she examined fell into groups, but concluded that none of the groups merit species rank but should perhaps be regarded merely as variants of Pseudomonas fluorescens.

All of the Pseudomonas strains tested in this laboratory have given a positive cytochrome oxidase test (Gaby \& Hadley, 1957) while Colwell \& Liston (1961) found that all of the strains within their four groups were positive by both the 
Table 2. Change of reaction produced by Pseudomonas and other species on incubation for $72 \mathrm{hr}$. in media containing Casitone+glucose + added nitrogenous compounds

\begin{tabular}{|c|c|c|c|c|c|}
\hline $\begin{array}{l}\text { Organisms } \\
P . \text { aeruginosa } 21 \text { strains }\end{array}$ & $\begin{array}{l}\text { Asparagine } \\
\text { alk }\end{array}$ & $\begin{array}{l}\text { Arginine } \\
\text { alk }\end{array}$ & $\begin{array}{l}\text { Leucinamide } \\
\text { alk }\end{array}$ & $\begin{array}{l}\text { Glycinamide } \\
\text { alk }\end{array}$ & $\begin{array}{l}\text { Alanine } \\
\text { 1-n } \\
2 \text {-a } \\
\text { 18-alk }\end{array}$ \\
\hline P. saccharophilia & alk & alk & alk & alk & $\mathbf{n}$ \\
\hline P. oleovorans & $\mathbf{n}$ & $\mathbf{n}$ & $\mathbf{n}$ & $\mathbf{n}$ & alk \\
\hline P. ovalis & alk & alk & $\mathbf{a}$ & $\mathbf{a}$ & $\mathbf{a}$ \\
\hline$P$. fragi & alk & alk & $\mathbf{a}$ & $\mathbf{a}$ & $\mathbf{a}$ \\
\hline P. fluorescens & alk & alk & alk & $\mathbf{a}$ & $\mathbf{a}$ \\
\hline P. mucidolens & a & $\mathbf{a}$ & $\mathbf{n}$ & $\mathbf{a}$ & $\mathbf{a}$ \\
\hline E. coli & $\mathbf{a}$ & $\mathbf{a}$ & $\mathbf{a}$ & a & $\mathbf{a}$ \\
\hline Salmonella* & $\mathbf{a}$ & $\mathbf{a}$ & $\mathbf{a}$ & $\mathbf{a}$ & $\mathbf{a}$ \\
\hline Shigella* & $\mathbf{a}$ & $\mathbf{a}$ & $\mathbf{a}$ & $\mathbf{a}$ & $\mathbf{a}$ \\
\hline Proteus* & $\mathbf{a}$ & $\mathbf{a}$ & $\mathbf{a}$ & $\mathbf{a}$ & $\mathbf{a}$ \\
\hline Organisms & Serine & Lysine & Methionine & $\begin{array}{c}\text { Glucose } \\
\text { (peptone- } \\
\text { base) }\end{array}$ & $\begin{array}{c}\text { Xylose } \\
\text { (peptone- } \\
\text { base) }\end{array}$ \\
\hline$P$. aeruginosa 21 strains & $2-n$ & $1-n$ & 4-n & $7-a$ & 2-a \\
\hline & 2-a & $1-\mathbf{a}$ & $1-\mathbf{a}$ & 14-n & $19-n$ \\
\hline & 17-alk & 19-alk & 16-alk & & \\
\hline P. saccharophilia & n & n & n & $\mathbf{a}$ & $\mathbf{a}$ \\
\hline P. oleovorans & $\mathbf{n}$ & $n$ & $\mathbf{n}$ & $\mathbf{n}$ & $\mathbf{n}$ \\
\hline P. ovalis & alk & $\mathbf{a}$ & $\mathbf{n}$ & $\mathbf{a}$ & $\mathbf{a}$ \\
\hline P. fragi & $\mathbf{a}$ & $\mathbf{a}$ & $\mathbf{a}$ & $\mathbf{a}$ & $\mathbf{a}$ \\
\hline P. fluorescens & $\mathbf{a}$ & $\mathbf{a}$ & $\mathbf{a}$ & $\mathbf{a}$ & $\mathbf{n}$ \\
\hline P. mucidolens & $\mathbf{a}$ & $\mathbf{a}$ & $\mathbf{a}$ & $\mathbf{a}$ & $\mathbf{n}$ \\
\hline E. coli & $\mathbf{a}$ & $\mathbf{a}$ & $\mathbf{a}$ & $\mathbf{a}$ & $\mathbf{a}$ \\
\hline Salmonella* & $\mathbf{a}$ & a & $\mathbf{a}$ & a & a \\
\hline Shigella* & a & a & $a$ & a & a \\
\hline Proteus* & a & a & a & a & a \\
\hline
\end{tabular}

alk = alkaline $\mathbf{a}=$ acid $; \mathbf{n}=$ neutral $;$ no change in indicator.

* Several strains and species tested.

oxidase test (Kovacs, 1956) and cytochrome oxidase test (Gaby \& Hadley, 1957). These results would seem to indicate that it should not be too difficult to identify a Gram-negative bacillus as a Pseudomonas. Proper emphasis, however, has not been placed on the catabolism of nitrogenous compounds by this group of microorganisms.

This investigation was supported in part by a research grant (E-3778) from the National Institute of Allergy and Infectious Diseases, U.S. Public Health Service.

\section{REFERENCES}

Bergey's Manual of Determinative Bacteriology. Ed. by R. S. Breed, E. D. G. Murray \& N. R. Smith (1957). 7th ed. Baltimore: The Williams and Wilkins Co.

Colwell, R. R. \& Liston, J. (1961). Taxonomic relationships among the Pseudomonads. J. Bact. 82, 1.

GaBY, W. L. \& FreE, E. (1953). Occurrence and identification of non-pigmented strains of Pseudomonas aeruginosa in the clinical laboratory. J. Bact. 65, 746.

GABY, W. L. \& Free, E. (1958). Differential diagnosis of Pseudomonas-like microorganisms in the clinical laboratory. J. Bact. 76, 442. 
Gaby, W. L. \& Hadley, D. (1957). Practical laboratory test for the identification of Pseudomonas aeruginosa. J. Bact. 74, 356.

Gaby, W. L. \& Logan, C. (1961). Pathogenicity of clinical strains of Pseudomonas aeruginosa for mice. J. Bact. 82, 149.

Kovacs, N. (1956). Identification of Pseudomonas pyocyanea by the oxidase reaction. Nature, Lond. 178, 703.

Rhodes, M. E. (1959). The characteristics of Pseudomonas flucrescens. J. gen. Microbiol. 21, 221.

Rhodes, M. E. (1961). The characterization of Pseudomonas fluorescens with the aid of an electronic computer. J. gen. Microbiol. 25, 331.

Sherris, J. C., Shoesmith, J. G., Parker, M. T. \& Breckon, D. (1959). 'Tests for the rapid breakdown of arginine by bacteria. 'Their use in the identification of Pseudomonads. J. gen. Microbiol. 21, 389.

Silberman, R. \& Gaby, W. L. (1961). The uptake of amino acids by lipids of Pseudomonas aeruginosa. J. Lipid Res. $2,172$.

Simon, R. D. (1956). The use of fermentation reactions and pigment production to differentiate between types of Pseudomonas pyocyanea and other Pseudomonas species, especially fluorescens. Brit. J. exp. Path. 37, 494.

Warren, R. A. J., Ells, A. F. \& Campbell, J. J. R. (1960). Endogenous respiration of Pseudomonas aeruginosa. J. Bact. 79, 875. 